\title{
Fikotoksini u morskim organizmima - potencijalna prijetnja sigurnosti potrošača
} K. Kvrgić, N. Džafić i J. Pleadin*

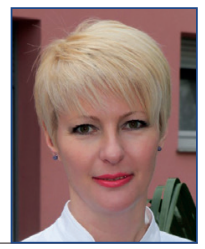

\section{Sažetak}

Fikotoksini predstavljaju skupinu prirodnih kemijskih kontaminanata $\mathrm{u}$ koje spadaju azaspiracidi(AZA), okadaična kiselina (OA) i njeni derivati, pektenotoksini (PTX), jesotoksini (YTX), ciklički imini (CI), domoična kiselina (DA), saksitoksini (STX), brevetoxini (BTX), ciguatoksini (CTX) i palitoksini (PITX). Rezultati dosadašnjih istraživanja ukazuju na učestalu pojavnost fikotoksina u morskim organizmima, a poznato je da ove tvari mogu imati štetan učinak na okoliš i zdravlje ljudi, budući da su pored akutne toksičnosti pojedini ujedno i tumor promotori, odnosno da već i u malim koncentracijama pokazuju mutageno i toksično djelovanje u organizmu. Stoga su s ciljem zaštite zdravlja potrošača zakonodavstvom određene najveće dopuštene količine (NDK) fikotoksina u školjkaša, bodljikaša, plaštenjaka i morskih puževa (EZ 853/2004; EU 786/2013), iako neki od njih, poput cikličkih imina, još nisu uključeni u programe monitoringa, odnosno za njih legislativom nije određena NDK. U daljnjim istraživanjima, uz primjenu potvrdnih visokospecifičnih analitičkih metoda $\mathrm{u}$ ispitivanjima pojavnosti fikotoksina, potrebno je ispitati njihove učinke na osjetljiviji dio populacije te zbog mogućeg sinergičkog učinka u organizmu ustvrditi i supojavnost, kaoi provesti procjenu izloženosti potrošača zbog prisustnosti ovih toksičnih tvari u različitim morskim organizmima namijenjenih konzumaciji. U ovom radu dan je pregled literaturnih spoznaja o svojstvima najznačajnijih predstavnika fikotoksina, njihovim toksičnim učincima $\mathrm{u}$ organizmu i pojavnosti u različitim vrstama morskih organizama.

Ključne riječi: fikotoksini, sigurnost potrošača, morski organizmi, pojavnost, toksičnost

\section{Uvod}

Plodovi mora, osim što su fina delicija, čine važan dio uravnotežene prehrane zbog brojnih pozitivnih učinaka na zdravlje. Karakterizira ih znatan udio

lako probavljivih bjelančevina te mali udio kolesterola i masti. Znatan su izvor polinezasićenih masnih kiselina te mnogih drugih mikronutrijenata,

Kristina KVRGIĆ, dipl. ing., stručna suradnica, mr. sc. Natalija DŽAFIĆ, dr. med. vet., stručna suradnica, Hrvatski veterinarski institut, Veterinarski zavod Rijeka, Rijeka, Hrvatska; dr. sc. Jelka PLEADIN*, dipl. ing. biotehnol., znanstvena savjetnica $u$ trajnom zvanju, izvanredna profesorica (dopisni autor, e-mail: pleadin@veinst.hr), Hrvatski veterinarski institut, Zagreb, Hrvatska 
vitamina i minerala (Dong, 2009., Oehlenschläger, 2012.). Mnoge se vrste plodova mora koristi kao izvor bioaktivnih komponenti u proizvodnji funkcionalne hrane i dodataka prehrani (Grienke i sur., 2014., Suleria, 2015.). Zbog visoke nutritivne vrijednosti i svjesnosti potrošača o njihovoj dobrobiti za zdravlje sve je veća potražnja za poznatim vrstama poput školjkaša, ali i manje poznatim jestivim vrstama, kao što su mješčićnice (podkoljeno plaštenjaka), koje odlikuje visoki udio bjelančevina i mala kalorijska vrijednost, naročito Microcosmus vrste, a bogati su vitaminima, mineralima i jodom (Meenakshi i sur., 2012., Lambert i sur., 2016.).

Međutim, osim navedenih koristi, konzumacija plodova mora za potrošače predstavlja i određeni rizik. Ukoliko su $\mathrm{u}$ moru prisutne vrste fitoplanktona koje produciraju toksine (morske biotoksine ili fikotoksine), morski organizmi postaju vektori i mogu izazvati intoksikacije u ljudi i životinja koji se njima hrane, a pritom su ključni organizmi poput školjkaša i plaštenjaka koji zbog načina hranidbe (filtracije velikih količina morske vode) u svom tkivu akumuliraju fikotoksine, čijom konzumacijom dolazi do intoksikacije (Costa i sur., 2017.). U ovim organizmima fikotoksini ne izazivaju vidljive promjene na temelju kojih bi potrošači mogli posumnjati $\mathrm{u}$ njihovu zdravstvenu ispravnost. Postoje dokazi da kronično izlaganje školjkaša subletalnim koncentracijama toksičnih vrsta fitoplanktoma može imati negativni utjecaj na njihovo razmnožavanje, rast i brzinu procesa eliminacije fikotoksina (Brown i sur., 2019.). Dokazano je da fikotoksine najčešće proizvode dinoflagelati roda Alexandrium, Gymnodinium, Dinophysis, Protoperidinium, Protoceratium, Karenia, Gambierdiscus, Ostreopsis te dijatomeje roda Pseudo-nitzchia (Ciminiello i sur., 2009.).
Ukoliko zbog okolišnih i klimatskih uvjeta dođe do njihove proliferacije i nakupljanja, fikotoksini mogu imati štetan učinak i na okoliš i na zdravlje ljudi. Pored akutne toksičnosti pojedini fikotoksini su i tumor promotori, dok neki već i u malim koncentracijama pokazuju mutageno i toksično djelovanje u organizmu (Manerio i sur., 2008., Prem Kumar i sur., 2009., Saeed i sur., 2017., Farabegoli i sur., 2018.). Stoga su s ciljem zaštite potrošača zakonodavstvom određene najveće dopuštene količine (NDK) fikotoksina u školjkaša, bodljikaša, plaštenjaka i morskih puževa (EZ 853/2004; EU 786/2013). Ujedno, neki od njih, poput cikličkih imina, nisu uključeni u programe monitoringa, niti je za njih legislativom određena NDK.

U ovom je radu prikazan pregled literaturnih spoznaja o svojstvima najznačajnijih predstavnika fikotoksina, njihovim toksičnim učincima $u$ organizmu i pojavnosti $u$ različitim vrstama morskih organizama.

\section{Najvažniji predstavnici i svojstva}

Fikotoksini su termostabilne, uglavnom neproteinske molekule malih do vrlo velikih molekulskih masa. Prema topljivosti dijele se na one topljive $\mathrm{u}$ vodi $\mathrm{i}$ na one topljive $\mathrm{u}$ mastima. Prema kemijskoj strukturi dijele se $\mathrm{u}$ osam skupina: azaspiracidi (AZA), okadaična kiselina (OA) i njeni derivati, pektenotoksini (PTX), jesotoksini (YTX), ciklički imini (CI), domoična kiselina (DA), saksitoksini (STX) i brevetoxini (BTX). Veliku skupinu čine ciguatoksini i palitoksini. Za razliku od prethodno navedenih, njihov vektor nisu organizmi koji se hrane filtracijom, već najčešće ribe i rakovi (Ciminiello i sur., 2009., Tubaro i sur., 2011., Farabegoli i sur., 2018.). $\mathrm{Na}$ slici 1. prikazani su predstavnici fikotoksina čija je pojavnost naznačajnija u području Jadrana. 
Okadaična kiselina i njezini derivati dinofizistoksini (DTX1, DTX2) te esterificirani oblici ovih toksina (DTX3 toksini) su termostabilne lipofilne, policikličke, polieterske karboksilne kiseline koje stvaraju mikroalge roda Dinophysis i Prorocentrum, a u literaturi su poznati kao skupina toksina koja prouzroči probavne smetnje - Diarrheic shellfish poisoning (DSP). Još su se dvije skupine polieterskih spojeva ranije svrstavale u DSP skupinu: pektenotoksini (PTX) i jesotoksini (YTX) zbog česte supojavnosti, zajedničke ekstrakcije u lipofilnoj frakciji uzoraka i istovremenom određivanju biološkim pokusom. Danas je poznato da ovi spojevi imaju različite biološke učinke (Reguera i Pizzaro, 2008.).

PTX su neutralni makrociklički polieter-laktoni koji se u školjkašima javljaju uvijek uz prisustvo okadaične skupine, a stvaraju ih nekoliko vrsta mikroalgi roda Dinophysis. Jesotoksini su polieterski laktoni koji u svojoj molekuli sadrže sumpor, a najčešće ih proizvode dinoflgelati vrste Protoceratium reticulatum, Lingulodinium polyedrum i Gonyaulax spinifera. Otkriveno je nešto manje od 100 analoga, od kojih jedan dio nastaje u dinoflagelatima, a ostali su metabolički produkti školjkaša (Farabegoli i sur., 2018.).

Ciklički imini (CI) su skupina lipofilnih fikotoksina za koju je karakteristično da sadrže spiro-spoj eterskih dijelova molekule te imino-skupinu koja je odgovorna za njihovu akutnu neurotoksičnost. U CI spadaju spirolidi (SPX), gimnodimini (GYM), pinatoksini (PnTX) i pteriatoksini (PtTX) te prorocentrolidi i spiro-prorocentrimini (Molgó i sur., 2017., RamblaAlegre i sur., 2018.). Proizvode ih nekoliko vrsta dinoflagelata roda Alexandrium i Symbiodinium te dinoflagelati Gymnodinium cf. mikimotoi, Karenia selliformis, Vulcanodinium rugosum i Prorocentrum lima (Farabegoli i sur., 2018.).

Azaspiracidi (AZA) su lipofilni toksini koje proizvode dinoflagelati roda
Azadinium i Amphidoma (Luckas i sur., 2017., Farabegoli i sur., 2018.) Poznato je oko 30 analoga, a s obzirom na njihovu pojavnost i toksičnost, najznačajniji su analozi AZA1, AZA2 i AZA3. Po strukturi ovi spojevi predstavljaju polieterske amino-kiseline $\mathrm{s}$ tri spirospoja u molekuli, heterocikličkom amino skupinom te terminalno smještenom alifatskom karboksilnom skupinom (Farabegoli i sur., 2018.). Osim što su termostabilni, stabilni su i u uvjetima snižene $\mathrm{pH}$ vrijednosti (Wu i sur., 2019.).

Brevetoksini (BTX) su lipofilnii ciklički polieterski spojevi koje uglavnom proizvode Karenia vrste dinoflagelata. Njihova pojavnost veže se uz područje Meksičkog zaljeva i Novog Zelanda, a u Europi nisu detektirani (Farabegoli i sur., 2018.). Dinoflagelati roda Ostreopsis proizvode palitoksin i njegove analoge. Neproteinska molekula palitoksina kompleksne je strukture i najveća među fikotoksinima $(2680,13$ Da). Sadrži i lipofilne i hidrofilne dijelove te najdulji poznat ugljikov lanac $u$ molekulama prirodnog podrijetla (Patocka i sur., 2018.). Ciguatoksini su lipofilni fikotoksini politeterske prstenaste strukture (Darracq, 2014.) koje proizvode dinoflagelati roda Gambierdiscus, a pojavnost im je ograničena uglavnom na tropska i suptropska područja (Caillaud i sur., 2010.).

Domoična kiselina i njezini analozi te saksitoksini, spadaju u skupinu hidrofilnih fikotoksina. DA prvi je put izolirana iz crvene alge Chondria armata, a zna se da ju proizvode sve vrste diatoma roda Pseudo-nitzschia, uz ostale srodne vrste. Spada u aminokiseline sa sekundarnom amino skupinom te sadrži tri karboksilne skupine. Strukturom je slična glutaminskoj kiselini što rezultira njezinim toksičnim djelovanjem. Do sada je otkriveno osam izomera DA (AH) i jedan diastereomer (C5') (Saeed i sur., 2017.). Saksitoksin i njegovi analozi (poznato ih je 57) (Wiese i 
sur., 2010., Farabegoli i sur., 2018.) su tetrahidropurinski, neproteinski, polarni spojevi koje uglavnom stvaraju dinoflagelati roda Alexandrium, Pyrodinium i Gymnodinium te pojedine prokariotske slatkovodne cijanobakterije (Raposoisur., 2020.).Ukiselimuvjetimasu stabilni (osim N-sulfokarbamoil toksina), a u alkalnim uvjetima lako oksidiraju. $S$ obzirom na strukturu molekule dijele se $\mathrm{u}$ četiri podskupine, koje se razlikuju i po toksičnosti (navedeni prema padajućoj vrijednosti): karbamati, dekarbamoil, N-sulfokarbamoil i deoksidekarbamoil toksini (Wu i sur., 2019.).

Budući da se radi o termostabilnim molekulama, termičkom se obradom ne umanjuje njihova toksičnost, dok se koncentracija lipofilnih toksina $\mathrm{u}$ tkivu zbog gubitka vode može i dvostruko povećati (EFSA, 2009.c). U slučaju hidrofilnih fikotoksina termičkom obradom dolazi do njihovog prijelaza u tekućinu u kojoj se kuhaju, što za posljedicu ima smanjenje koncentracije u tkivu. U pojedinih vrsta, poput kapica moguća je i redistribucija iz hepatopankreasa $u$ druga tkiva $u$ kojima se posljedično koncentracija povećava (EFSA, 2009.a, 2009.c). U literaturi su navedene različite metode uklanjanja i smanjivanja koncentracije fikotoksina u živim školjkašima poput depuracije u čistoj vodi, tretiranja vode ozonom, promjene saliniteta, temperature, snižavanja $\mathrm{pH}$, kloriranja, kuhanja, smrzavanja, ali pokazale su se nesigurnima, presporima i ekonomski neisplativima (FAO, 2004.). Izuzetak su metode reduciranja koncentracije STX termičkom obradom prugaste kapice i japanske kamenice koje su objavili Berenguer i sur. (1993.) i Takata i sur. (1994.).

\section{Toksični učinci}

Vrsta i intenzitet simptoma akutne intoksikacije ovise o vrsti i količini unesenog fikotoksina te osjetljivosti

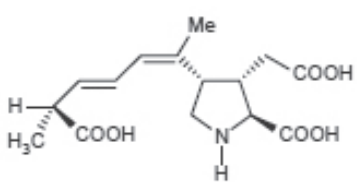

DOMOIČNA KISELINA

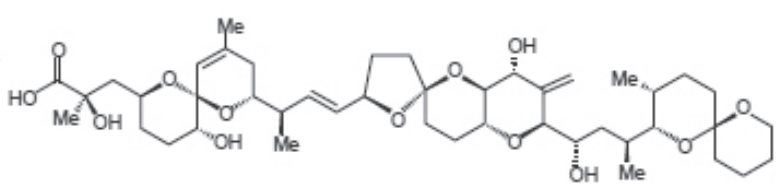

OKADAIČNA KISELINA

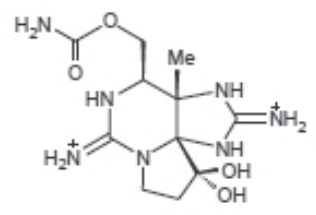

SAKSITOKSIN

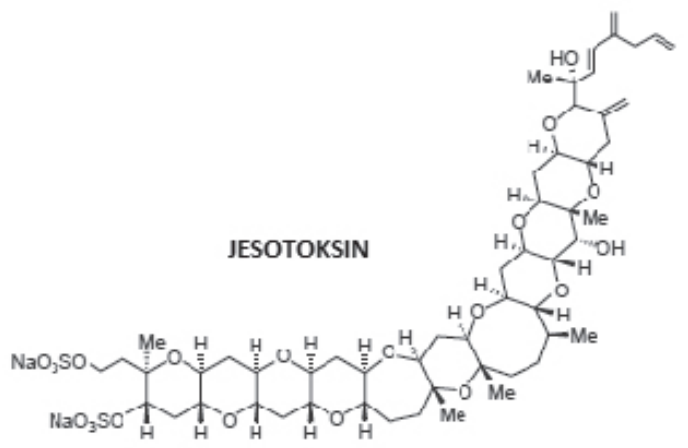

Stika 1. Strukture najznačajnijih predstavnika fikotoksina u Jadranskom moru 
organizma (Visciano i sur., 2016.). Često su simptomi slični onima koje prouzroče mikrobiološki kontaminanti i ne prepoznaju se kao intoksikacije fikotoksinima, što uz neobvezno prijavljivanje epidemiološkim službama doprinosi pogrešnoj slici o štetnim učincima ovih tvari u organizmu (EFSA, 2009.a, O'Mahony, 2018.).

Prema simptomima ili sindromima koje prouzroče, fikotoksini se mogu podijeliti u nekoliko skupina. Skupinu koja prouzroči probavne smetnje (engl. Diarrheic Shellfish Poisoning (DSP)) čine okadaična kiselina, dinofizistoksini (DTX1, DTX2) i njihovi esterificirani oblici (DTX3). Djeluju kao inhibitori enzima protein fosfataze 1 (PP1) i 2A (PP2A), narušavaju duodenalnu paracelularnu propusnost i prouzroče upalne procese $\mathrm{u}$ probavnom sustavu. Glavni simptomi trovanja su: proljev, mučnina, povraćanje i grčevi (Farabegoli i sur., 2018.). Pretpostavlja se da je toksično djelovanje OA u crijevima kompleksno te da uključuje i druge proteine pored PP (Wang i sur., 2012.). Pored akutne toksičnosti, OA i DTX1 su promotori rasta tumorskih stanica, što se dovodi u vezu s time da u niskim koncentracijama stimuliraju sekreciju upalnih supstanci (del Campo i sur., 2017.), a postoje dokazi i o citotoksičnom, imunotoksičnom, embriotoksičnom te neurotoksičnom djelovanju OA (Valdiglesias i sur., 2013.). PTX izazivaju promjene na citoskeletonu mijenjajući $\mathrm{F}$-aktin $\mathrm{u}$ različitim vrstama stanica, dok YTX utječu na staničnu regulaciju kalcijevih iona i koordinaciju fosfodiesteraze, a ciljne su stanice srčanog mišića (Farabegoli i sur., 2018.). Iako nema podataka o toksičnom učinku ovih dviju skupina fikotoksina na ljude, zbog navedenog štetnog učinka i dokazane akutne toksičnosti na pokusnim životinjama, potrebno je praćenje njihove koncentracije $\mathrm{s}$ ciljem zaštite zdravlja, naročito osjetljivog dijela populacije poput srčanih bolesnika
(Ciminiello i Fatturosso, 2008., Suzuki, 2008., Farabegoli i sur., 2018.).

Azaspiracidno trovanje školjkašima (AZP) po simptomima je slično sindromu DSP, no mehanizam djelovanja ovih toksina, je još uvijek nepoznat. Proljev, mučnina, povraćanje i grčevi javljaju se nekoliko sati nakon unosa $\mathrm{u}$ organizam. Dokazana je citotoksičnost, neurotoksičnost i kardiotoksičnost AZA (Farabegoli i sur., 2018.). CI su otkriveni među posljednjima te još nema podataka o negativnim učincima na zdravlje ljudi, ali ni o njihovoj kroničnoj toksičnosti. Međutim, poznato je da predstavljaju brzo djelujuće neurotoksične toksine koji vrlo brzo nakon intraperitonealne aplikacije lipofilnog ekstrakta izazivaju smrt pokusnih životinja (EFSA, 2010.). Neurotoksično djelovanje iskazuju inhibiranjem muskarinskih i nikotinskih receptora (Farabegoli i sur., 2018.).

DA i njezini analozi su ekscitatorni neurotoksini čije toksično djelovanje proizlazi iz strukturne sličnosti s glutaminskom kiselinom. Kao agonisti glutamata vežu se na kainatne receptore i izazivaju depolarizaciju neurona. Glavni simptom koji izaziva je gubitak kratkoročnog pamćenja po čemu je ovo trovanje i dobilo naziv Amnesic shellfish poisoning (ASP), uz epileptičke napadaje, vrtoglavicu, mučninu, povraćanje te u težim slučajevima komu ili smrt (Farabegoli i sur., 2018.). Trovanje školjkašima koje prouzroči paralizu (PSP) prouzroči skupina toksina koju čine saksitoksin (STX) i njegovi analozi. Mehanizam djelovanja najtoksičnijeg u ovoj skupini - STX, je blokiranje neuronske aktivnosti čvrstim vezanjem na mjesto receptora u naponski reguliranim natrijevim kanalima (Wu i sur., 2019.). Simptomi trovanja su gastrointestinalni i neurološki, u rasponu od blagih poput utrnulosti, trnaca i glavobolje, do težih kao što su poteškoće u disanju, paraliza, gušenje i smrt (FAO, 2004., EFSA, 2009.b, 
Wiese i sur., 2010.).

Brevetoksini (BTX) su neurotoksini koji izazivaju sindrom neurotoksičnog trovanja školjkašima (NSP) za koje su karakteristični neurološki simptomi (poteškoće s hodanjem, koordinacijom, govorom, ataksija) te nespecifični gastrointestinalni simptomi. Skoro identične simptome izazivaju i ciguatoksini. Palitoksini se vežu na natrij-kalij pumpu stanične membrane te izazivaju nekontrolirani transport iona kroz membranu. Simptomi trovanja su gastrointestinalni i neurološki, a u težim slučajevima moguć je i smrtni ishod (Farabegoli i sur., 2018.).

$S$ obzirom na toksičnost i bioraspoloživost svi analozi nemaju jednak učinak. Stoga se za izračun ukupne toksičnosti i procjenu rizika primjenjuje faktor ekvivalentne toksičnosti (TEF), koji predstavlja omjer toksičnosti analoga $\mathrm{u}$ odnosu na referentni toksin pojedine skupine (FAO, 2016., Botana i sur., 2017.).

\section{Pojavnost u svijetu}

Zbog globalnih klimatskih promjena i antropogenog utjecaja sve je veća učestalost i rasprostranjenost štetnog cvjetanja algi (Van Dolah, 2000., FAO, 2004., Farabegoli i sur., 2018.), što za posljedicu ima češću pojavnost i veći broj vrsta fikotoksina u morskim organizmima, čak i u područjima u kojima do sada nisu bili prisutni. Vrsta i maseni udio fikotoksina prisutnih $u$ školjkašima, tzv. profil fikotoksina, ovisi o vrsti prisutnog fitoplanktona, vrsti školjkaša i specifičnostima lokaliteta, a podložan je promjenama ne samo zbog različite raspoloživosti hranjivih tvari tijekom godišnjih doba, već i klimatskih i antropogenih utjecaja kroz duži vremenski period (Bacchiocchi i sur., 2015., Bazzoni i sur., 2016.).

Od početka 90-tih godina prošlog stoljeća kada je i započelo istraživanje profila fikotoksina $\mathrm{u}$ sjevernom dijelu Jadrana, u školjkašima podrijetlom s tog područja, sve do sredine 90-tih dominirali su DTX i OA, kada su najčešći kontaminanti postali YTX. DA se pojavila 2000. godine, nekoliko godina kasnije i SPX (Ciminiello i sur., 2010.), a dokazana je i pojavnost gimnodimina i pinatoksina (Kvrgić i sur., 2021.). U proljeće 1994. godine prvi je put zabilježena pojava STX (Ujević i sur., 2012.). Navedena istraživanja ukazuju na kompleksnost profila fikotoksina u školjkaša podrijetlom s ovog područja, koji se tijekom godina mijenjao. Pojava novih vrsta toksina predstavlja i novi rizik za potrošače te je stoga ispitivanje njihove pojavnosti u školjkašima neophodno za procjenu rizika i izloženosti potrošača ovim kontaminantima.

Štetno cvjetanje algi u svijetu je izazvalo mnogo slučajeva intoksikacije fikotoksinima, a neki od njih prikazani su u tabelama 1 i 2 . Prikazane su najveće koncentracije fikotoksina u slučajevima u kojima je došlo do pojave sindroma DSP, PSP i ASP u ljudi ili životinja te oni u kojima sindromi nisu potvrđeni, ali su $\mathrm{u}$ morskim organizmima na pojedinom području ustvrđene njihove vrlo visoke koncentracije. Uz trovanje ciguatera toksinom, DSP je najčešći sindrom izazvan fikotoksinima, dok su trovanje tetrodotoksinom i STX najsmrtonosniji. Vidljivo je da je pojavnost većine skupina fikotoksina zabilježena u skoro svim svjetskim morima. Najveći broj slučajeva sindroma DSP zabilježen je u Europi i sjevernoj Americi, PSP u sjevernoj i južnoj Americi, dok se ASP najčešće pojavljuje na Pacifiku, atlantskoj obali sjeverne i centralne Amerike te Europe (Nicolas i sur., 2017., Brown i sur., 2019.).

Iako su školjkaši zbog načina hranidbe najčešći vektori fikotoksina, dokazano je da to mogu biti i drugi morski organizmi, poput riba, rakova, morskih puževa i plaštenjaka (Pitcher i sur., 2001., Deeds i sur., 2008., Roje- 
Tabela 1. Podatci o dokazanoj pojavnosti lipofilnih fikotoksina u morskim organizmima diljem svijeta

\begin{tabular}{|c|c|c|c|c|c|}
\hline Država & Fikotoksin & Koncentracija & Vrsta & Godina & Referenca \\
\hline Kanada & OA & $5,2 \mathrm{mg} / \mathrm{kg}$ & dagnja & 2003. & Bates i sur., 2020. \\
\hline Kanada & DTX1, DTX3 & $860 \mu \mathrm{g} / \mathrm{kg}$ & dagnja & 2011. & Taylor i sur., 2013. \\
\hline Južna Afrika & OA & $267 \mu \mathrm{g} / \mathrm{kg}$ & dagnja & 2008. & Pitcher i sur., 2011. \\
\hline Australija & $\mathrm{OA}$ & $253 \mu \mathrm{g} / \mathrm{kg}$ & kamenica & 2003. & Ajani i sur., 2017. \\
\hline Kina & $\begin{array}{c}\text { OA } \\
\text { DTX1 }\end{array}$ & $\begin{array}{l}635 \mu \mathrm{g} / \mathrm{kg} \\
86 \mu \mathrm{g} / \mathrm{kg}\end{array}$ & dagnja & 2011. & Chen i sur., 2013. \\
\hline Danska $^{a}$ & $\mathrm{OA}$ & $1,7 \mathrm{mg} / \mathrm{kg}$ & dagnja & 1990. & FAO, 2004. \\
\hline Irska & $\begin{array}{c}\text { OA } \\
\text { DTX2 }\end{array}$ & $\begin{array}{c}<700 \mu \mathrm{g} / \mathrm{kg} \\
6,3 \mathrm{mg} / \mathrm{kg}\end{array}$ & dagnja & $\begin{array}{l}1991 .- \\
1994 .\end{array}$ & Economou i sur., 2007. \\
\hline $\begin{array}{l}\text { Ujedinjeno } \\
\text { Kraljevstvo }\end{array}$ & OA & $367 \mu \mathrm{g} / \mathrm{kg}$ & dagnja & 1997. & Economou i sur., 2007. \\
\hline Hrvatska & $\begin{array}{c}\text { OA } \\
\text { DTX-2 }\end{array}$ & $\begin{array}{l}133 \mu \mathrm{g} / \mathrm{kg} \\
100 \mu \mathrm{g} / \mathrm{kg}\end{array}$ & dagnja & 1997. & Economou i sur., 2007. \\
\hline Španjolska & OA & $10,1 \mathrm{mg} / \mathrm{kg}$ & dagnja & 1998. & Economou i sur., 2007. \\
\hline Portugal & $\mathrm{OA}$ & $18,62 \mathrm{mg} / \mathrm{kg}$ & dagnja & 2002. & Economou i sur., 2007. \\
\hline
\end{tabular}

OA-okadaična skupina; DTX-dinofizistoksin

a školjke uvezene iz Francuske

Tabela 2 Podatci o dokazanoj pojavnosti hidrofilnih fikotoksina u morskim organizmima diljem svijeta

\begin{tabular}{|c|c|c|c|c|c|}
\hline Država & Fikotoksin & Koncentracija & Vrsta & Godina & Referenca \\
\hline Kanada & STX & $\begin{array}{c}67 \text { mg STXeq/ } \\
\text { kg }\end{array}$ & dagnja & 2000. & Cembella i sur., 2002. \\
\hline Južna Afrika & STX & $\begin{array}{l}16,09 \mathrm{mg} \\
\text { STXeq/kg }\end{array}$ & $\begin{array}{l}\text { petrovo } \\
\text { uho }\end{array}$ & 1999. & Pitcher i sur., 2001. \\
\hline Australija & STX & $\begin{array}{c}35 \text { mg STXeq/ } \\
\text { kg }\end{array}$ & dagnja & 2015. & Edwards i sur., 2018. \\
\hline Čile & STX & $\begin{array}{l}87,63 \mathrm{mg} \\
\mathrm{STXeq} / \mathrm{kg}\end{array}$ & koritnica & 2016. & Álvarez i sur., 2019. \\
\hline Španjolska & STX & $\begin{array}{c}40 \text { mg STXeq/ } \\
\text { kg }\end{array}$ & dagnja & 1976. & IPCS, 1984. \\
\hline UK & STX & $\begin{array}{c}36,5 \mathrm{mg} \\
\text { STXeq/kg }\end{array}$ & dagnja & 1990. & Davidson i sur., 2011. \\
\hline Hrvatska & STX & $\begin{array}{c}1,55 \mathrm{mg} \\
\text { STXeq/kg }\end{array}$ & dagnja & 2009. & Ujević i sur., 2012. \\
\hline Portugal & STX & $\begin{array}{c}38 \text { mg STXeq/ } \\
\text { kg }\end{array}$ & dagnja & 2018. & $\begin{array}{c}\text { de Carvalho i sur., } \\
2019 .\end{array}$ \\
\hline Kanada & DA & 1280 mg/kg & dagnja & 1987. & Todd, 1997. \\
\hline Čile & DA & 103 mg/kg & kapica & 2006. & Diaz i sur., 2019. \\
\hline Filipini & DA & $80,92 \mathrm{mg} / \mathrm{kg}$ & kopito & 2006. & Takata i sur., 2009. \\
\hline Irska & DA & $240 \mathrm{mg} / \mathrm{kg}$ & kapica & $\begin{array}{l}\text { 1999.- } \\
2000 .\end{array}$ & James i sur., 2005. \\
\hline Francuska & DA & $53 \mathrm{mg} / \mathrm{kg}$ & $\begin{array}{c}\text { D. } \\
\text { trunculus }\end{array}$ & 2000. & Amzil i sur., 2001. \\
\hline
\end{tabular}

STX-saksitoksini; DA-domoična kiselina 
Busatto i Ujević, 2014.). Budući da štetno cvjetanje algi nije moguće predvidjeti važno je provoditi kontinuirano praćenje pojavnosti fikotoksina u školjkašima i drugim morskim organizmima. Temeljem godišnje propisanih programa monitoringa Ministarstva poljoprivrede značajno se smanjuje udio kontaminiranih školjkaša na hrvatskom tržištu, što nedvojbeno rezultira i zaštitom zdravlja potrošača.

\section{Zaključci i budući aspekti}

Prisutnost fikotoksina $\mathrm{u}$ morskim organizmima predstavlja prijetnju za zdravlje i ljudi i životinja. Buduća istraživanja $u$ ovom području za cilj trebaju imati i ustvrditi pojavnost i koncentraciju hidrofilnih i lipofilnih skupina fikotoksina u najčešće uzgajanim i izlovljavanim vrstama školjkaša kao što su: dagnje, kamenice i male kapice te manje eksploatiranim, ali nutritivno jednako vrijednim pridnenim organizmima, kao što su mješčićnice. Zakonodavstvom su ustvrđene NDK, ali potrebno je i istražiti učinke ovih spojeva na osjetljiviji dio populacije djece, starijih osoba, trudnica i bolesnika s kroničnim oboljenjima. Zbog zaštite zdravlja potrošača potrebno je imati pouzdane i precizne suvremene analitičke metode za ispitivanje pojavnosti što većeg broja fikotoksina, a to podrazumijeva primjenu metoda sa što nižim limitima detekcije (LOD) i kvantifikacije (LOQ) ovih toksina. Važno je zbog njihovog mogućeg sinergičkog učinka u organizmu ispitati i supojavnost različitih fikotoksina, kao i provesti procjenu izloženosti potrošača zbog prisustva ovih toksičnih tvari $\mathrm{u}$ različitim morskim organizmima namijenjenih konzumaciji.

\section{Literatura}

1. AJANI, P., D. T. HARWOOD and S. A. MURRAY (2017): Recent Trends in Marine Phycotoxins from Australian CoastalWaters. Mar. Drugs. 15, 33.
2. ÁlVAREZ, G., P. A. DÍAZ, M. GODOY, M. ARAYA, I. GANUZA, R. PINO, F. ÁLVAREZ, J. RENGEL, C. HERNÁNDEZ, E. URIBE and J. BLANCO (2019): Paralytic Shellfish Toxins in Surf Clams Mesodesma donacium during a Large Bloom of Alexandrium catenella Dinoflagellates Associated to an Intense Shellfish Mass Mortality. Toxins 11, 188.

3. AMZIL, Z., J. FRESNEL, D. LE GAL and C. BILLARD (2001): Domoic acid accumulation in French shellfsh in relation to toxic species of Pseudonitzschia multiseries and $P$. pseudodelicatissima. Toxicon. 39, 1245-1251.

4. BACCHIOCCHI, S., M. SIRACUSA, A. RUZZI, S. GORBI, M. ERCOLESSI, M. A. COSENTINO, P. AMMAZZALORS and R. ORLETTI (2015): Twoyear study of lipophilic marine toxin profile in mussels of the North-central Adriatic Sea: First report of azaspiracids in Mediterranean seafood. Toxicon. 108, 115-125.

5. BATES, S. S., D. G. BEACH, L. A. COMEAU, N. HAIGH, N. I. LEWIS, A. LOCKE, J. L. MARTIN, P. MCCARRON, C. H. MCKENZIE, C. MICHEL et al. (2020): Marine harmful algal blooms and phycotoxins of concern to Canada. Can. Tech. Rep. Fish. Aquat. Sci. 3384, 322 p.

6. BAZZONI, A. M., A. G. MUDADU, G. LORENZONI, I. ARRAS, A. LUGLIÈ, B. VIVALDI, V. CICOTELLI, G. SANNA, G. TEDDE, S. LEDDA, E. ALESSO, E. MARONGIU and S. VIRGILIO (2016): Occurrence of harmful algal species and shellfish toxicity in Sardinia (Italy). Ital. J. Food Saf. 5, 194-199.

7. BERENGUER, J. A., L. GONZALEZ, I. JIMENEZ, T. M. LEGARDA, J. B. OLMEDO and P. A BURDASPAL (1993): The effect of commercial processing on the paralytic shellfish poison (PSP) content of naturally contaminated Acanthocardia tuberculatum L. Food Addit. Contam. 10, 217-230.

8. BOTANA, L. M., P. HESS, R. MUNDAY, A. NATHALIE, S. L. DEGRASSE, M. FEELEY, T. SUZUKI, M. VAN DEN BERG, V. FATTORI, E. GARRIDO GAMARRO et al. (2017): Derivation of toxicity equivalency factors for marine biotoxins associated with Bivalve Molluscs. Trends Food Sci. Tech. 59, 15-24.

9. BROWN, A. R., M. LILLEY, J. SHUTLER, C. LOWE, Y. ARTIOLI, R. TORRES, E. BERDALET and C. R. TYLER (2019): Assessing risks and mitigating impacts of harmful algal blooms on mariculture and marine fisheries. Rev. Aquacult. 12, 1663-1688.

10. CAILLAUD, A., P. DE LA IGLESIA, H. T. DARIUS, S. PAUILLAC, K. ALIGIZAKI, S. FRAGA, M. CHINAIN and J. DIOGÈNE (2010): Update on Methodologies Available for Ciguatoxin Determination: Perspectives to Confront the Onset of Ciguatera Fish Poisoning in Europe [1]. Mar. Drugs. 8, 1838-1907.

11. CEMBELlA, A. D., M. A. QUILliAM, N. I. LEWIS, A. G. BAUDER, C. DELL'AVERSANO, K. THOMAS, J. JELLETT and R. R. CUSACK (2002): The toxigenic marine dinoflagellate Alexandrium 
tamarense as the probable cause of mortality of caged salmon in Nova Scotia. Harmful Algae 1, 313-325.

12. CHEN, T., X. XU, J. WEI, J. CHEN, R. MIU, L. HUANG, X. ZHOU, Y. FU, R. YAN, Z. WANG, B. LIU and F. HE (2013): Food-Borne Disease Outbreak of Diarrhetic Shellfish Poisoning Due to Toxic Mussel Consumption: The First Recorded Outbreak in China. PLoS ONE 8(5).

13. CIMINIELLO, P. and E. FATTORUSSO (2008): Yessotoxins, Chemistry, Metabolism, and Chemical Analysis. In: Botana, L. M.: Seafood and Freshwater Toxins, Pharmacology, Physiology and Detection. CRC Press, Boca Raton (287-314).

14. CIMINIELLO, P., C. DELL'AVERSANO, E. FATTORUSSO and M. FORINO (2009): Recent Developments in Mediterranean Harmful Algal Events. In: Fishbein J. C.: Advances in Molecular Toxicology, Vol. 3. Oxford, Elsevier B.V. (1-41).

15. CIMINIELLO, P., C. DELL'AVERSANO, E. FATTORUSSO, M. FORINO, L. TARTAGLIONE, L. BOSCHETTI, S. RUBINI, M. CANGINI, S. PIGOZZI, R. POLETTI (2010): Complex toxin profile of Mytilus galloprovincialis from the Adriatic sea revealed by LC-MS. Toxicon. 55, 280-288.

16. COSTA, P. R., S. T. COSTA, A. C. BRAGA, S. M. RODRIGUES and P. VALE (2017): Relevance and challenges in monitoring marine biotoxins in nonbivalve vectors. Food Control. 76, 24-33.

17. DARRACQ, M. A. (2014): Ciguatoxin. In: Wexler, P.: Encyclopedia of Toxicology, Vol. 1. Cambridge, Academic Press (963-965).

18. DAVIDSON, K., P. TETT and R. GOWEN (2011): Harmful Algal Blooms. In: Hester, R. E. and R. M. Harrison: Marine Pollution and Human Health. RSC Publishing, Cambridge (95-128).

19. DE CARVALHO, I. L., A.PELERITO, I. RIBEIRO, R. CORDEIRO, M. SOFIA NÚNCIO and P. VALE (2019): Paralytic shellfish poisoning due to ingestion of contaminated mussels: A 2018 case report in Caparica (Portugal). Toxicon: X. Vol. 4. https://doi. org/10.1016/j.toxcx.2019.100017

20. DEEDS, J.R., J. H. LANDSBERG, S. M. ETHERIDGE, G. C. PITCHER and S. W. LONGAN (2008): Non-Traditional Vectors for Paralytic Shellfish Poisoning. Mar. Drugs 6, 308-348.

21. DEL CAMPO, M., T. ZHONG, R. TAMPE, L. GARCÍA and N. LAGOS (2017): Sublethal doses of dinophysistoxin- 1 and okadaic acid stimulate secretion of inflammatory factors on innate immune cells: Negative health consequences. Toxicon. 126, 23-31.

22. DÍAZ, P. A., G. ÁLVAREZ, D. VARELA, I. PÉREZSANTOS, M. DÍAZ, C. MOLINET, M. SEGUEL, A. AGUILERA-BELMONTE, L. GUZMÁN, E. URIBE, J. RENGEL, C. HERNÁNDEZ, C. SEGURA and R. I. FIGUEROA (2019): Impacts of harmful algal blooms on the aquaculture industry: Chile as a case study. PiP. 6, 39-50.

23. DONG, F. M. (2009): The Nutritional Value of Shellfish. In: Fisheries, Aquaculture and Seafood. Washington, Sea Grant.
24. ECONOMOU, V., C. PAPADOPOULOU, M. BRETT, A. KANSOUZIDOU, K. CHARALABOPOULOS, G. FILIOUSSIS and K. SEFERIADIS (2007): Diarrheic shellfish poisoning due to toxic mussel consumption: first recorded outbreak in Greece. Food Addit. Contam. 23, 297-305.

25. EDWARDS, L. J., K. WILSON and M. G. K. VEITCH (2018): An Outbreak of Paralytic Shellfish Poisoning in Tasmania. Commun. Dis. Intell. 42.

26. EFSA (European Food Safety Authority) (2009a): Scientific Opinion of the Panel on Contaminants in the Food Chain on a request from the European Commission on Marine Biotoxins in Shellfish Summary on regulated marine biotoxins. EFSA J. 1306, 1-23.

27. EFSA (European Food Safety Authority) (2009b): Scientific Opinion of the Panel on Contaminants in the Food Chain on a request from the European Commission on Marine Biotoxins in Shellfish Saxitoxin Group. EFSA J. 1019, 1-76.

28. EFSA (European Food Safety Authority) (2009c): SCIENTIFIC OPINION Influence of processing on the levels of lipophilic marine biotoxins in bivalve molluscs. EFSA J. 1006, 1-10.

29. EFSA (European Food Safety Authority) (2010): Scientific Opinion on marine biotoxins in shellfish - Cyclic imines (spirolides, gymnodimines, pinnatoxins and pteriatoxins). EFSA J. 8(6), 1628.

30. EZ (Europska Zajednica) (2004): Uredba EZ br. 853/2004 Europskog parlamenta i Vijeća od 29. travnja 2004. o utvrđivanju određenih higijenskih pravila za hranu životinjskog podrijetla. OJ L 139, 30.04.2004., 55. Dostupno na: https:// eur-lex.europa.eu/legal-content/HR/TXT/ PDF/?uri=CELEX:02004R0853-20160401\&from=HR.

31. EZ (Europska Zajednica) (2013): Uredba Komisije (EU) br. 786/2013 o izmjeni Priloga III. Uredbi (EZ) br. 853/2004 Europskog parlamenta i Vijeća u pogledu dopuštenih granica yesotoksina u živim školjkama. OJ L 220, 17.8.2013., 14-14. Dostupno na: https:/eur-lex.europa.eu/legal-content/HR/TXT/ PDF/?uri=CELEX:32013R0786\&from=HR.

32. FARABEGOLI, F., L. BLANCO, L. P. RODRÍGUEZ, J. M. VIEITES and A. G. CABADO (2018): Phycotoxins in Marine Shellfish: Origin, Occurrence and Effects on Humans. Mar. Drugs. 16, 188.

33. FAO (Food And Agriculture Organization Of The United Nations) (2004): Marine biotoxins. Fao Food and Nutrition Paper 80. Dostupno na: http://www. fao.org/docrep/007/y5486e/y5486e00.htm.

34. FAO/WHO (Food And Agriculture Organization Of The United Nations/ World Health Organization) (2016): Technical paper on Toxicity Equivalency Factors for Marine Biotoxins Associated with Bivalve Molluscs. 108. Dostupno na: http://www. fao.org/3/i5970e/i5970e.pdf.

35. GRIENKE, U., J. SILKE and D. TASDEMIR (2014): Bioactive compounds from marine mussels and their effects on human health. Food Chem. 142, 48-60.

36. IPCS (International Programme on Chemical Safety) (1984): Aquatic (Marine and Freshwater) 
Biotoxins. Environmental Health Criteria 37. World Health Organization. Dostupno na: http:// www.inchem.org/documents/ehc/ehc/ehc37. htm\#SubSectionNumber:1.6.1.

37. JAMES, K. J., M. GILLMAN, M. FERNÁNDEZ AMANDI, A. LÓPEZ-RIVERA, P. FERNÁNDEZ PUENTE, M. LEHANE, S. MITROVIC and A. FUREY (2005): Amnesic shellfish poisoning toxins in bivalve molluscs in Ireland. Toxicon. 46, 852-858.

38. KVRGIĆ, K., T. LEŠIĆ, A. I. AYSAL, N. DŽAFIĆ and J. PLEADIN (2021): Cyclic imines in shellfish and ascidians in the northern Adriatic Sea. Food Addit. Contam. Part B Surveill. 14, 12-22.

39. LAMBERT, G., R. C. KARNEY, W. Y. RHEE and M. R. CARMAN (2016): Wild and cultured edible tunicates: a review. Manag. Biol. Invasions. 7, 59-66.

40. LUCKAS, B., T. KRÜGER and K. RÖDER (2017): Phycotoxins and Food Safety. In: D. Schrenk, D. and A. Cartus: Chemical Contaminants and Residues in Food. Woodhead Publishing, Sawston (337-378).

41. MANERIO, E., V. L. RODAS, E. COSTAS and J. M. HERNANDEZ (2008): Shellfish consumption: A major risk factor for colorectal cancer. Med. Hypotheses 70, 409-412.

42. MEENAKSHI, V. K., S. GOMATHY, S. SENTHAMARAI, M. PARIPOORANASELVI and K. P. CHAMUNDESWARI (2012): Analysis of vitamins by hplc and phenolic compounds, flavonoids by HPTLC in Microcosmus Exasperatus. Eur. J. Zool. Res. 1, 105-110.

43. MOLGÓ, J., P. MARCHOT, R. ARÁOZ, E. BENOIT, B. I. IORGA, A. ZAKARIAN, P. TAYLOR, Y. BOURNE and D. SERVENT (2017): Cyclic imine toxins from dinoflagellates: family of potent antagonists of the nicotinic acetylcholine receptors. J. Neurochem. 142, 41-51.

44. NICOLAS, J., R. L. A. P. HOOGENBOOM, P. J. M. HENDRIKSEN, M. BODERO, T. F. H. BOVEE, I. M. C. M. RIETJENS and A. GERSSEN (2017): Marine biotoxins and associated outbreaks following seafood consumption: Prevention and surveillance in the 21st century. Glob. Food Sec. 15, 11-22.

45. OEHLENSCHLÄGER, J. (2012): Seafood: Nutritional Benefits and Risk Aspects. Int. J. Vitam. Nutr. Res. 82, 168-176.

46. O'MAHONY, M. (2018): EU Regulatory Risk Management of Marine Biotoxins in the Marine Bivalve Mollusc Food-Chain. Toxins 10, 118.

47. PATOCKA, J., Q. WU and K. KUCA (2018): Palytoxin. In: Liu, Dong: Handbook of Foodborne Diseases, CRC Press, Boca Raton, (1035-1041).

48. PITCHER, G. C., J. M. FRANCO, G. J. DOUCETTE, C. L. POWELL and A. MOUTON (2001): Paralytic Shellfish Poisoning in the Abalone Haliotis midae on the West Coast of South Africa. J. Shellfish Res. 20, 895-904.

49. PITCHER, G. C., B. KROCK and A. D. CEMBELLA (2011): Accumulation of diarrhetic shellfish poisoning toxins in the oyster Crassostrea gigas and the mussel Choromytilus meridionalis in the southern Benguela ecosystem. Afr. J. Mar. Sci. 33, 273-281.
50. PREM KUMAR, K., S. PREM KUMAR and G. ACHUTHAN NAIR (2009): Risk assessment of the amnesic shellfish poison, domoic acid, on animals and humans. J. Environ. Biol. 30, 319-325.

51. RAMBLA-ALEGRE, M., C. O. MILES, P. DE LA IGLESIA, M. FERNANDEZ-TEJEDOR, S. JACOBS, I. SIOEN, W. VERBEKE, I. A. SAMDAL, M. SANDVIK, V. BARBOSA et al. (2018): Occurrence of cyclic imines in European commercial seafood and consumers risk assessment. Environ. Res. 161, 392-398.

52. RAPOSO, M. I. C., M. T. S. R. GOMES, M. JOÃO BOTELHO and A. RUDNITSKAYA (2020): Paralytic Shellfish Toxins (PST)-Transforming Enzymes: A Review. Toxins. 12, 344.

53. REGUERA, B. and G. PIZARRO (2008): Planktonic Dinoflagellates That Contain Polyether Toxins of the Old "DSP Complex". In: Botana, L. M.: Seafood and Freshwater Toxins, Pharmacology, Physiology and Detection. CRC Press, Boca Raton (258-284).

54. ROJE-BUSATTO, R. and I. UJEVIĆ (2014): PSP toxins profile in ascidian Microcosmus vulgaris (Heller, 1877) after human poisoning in Croatia (Adriatic Sea). Toxicon. 79, 28-36.

55. SAEED, A. F., S. A. AWAN, S. LING, R. WANG and S. WANG (2017): Domoic acid: Attributes, exposure risks, innovative detection techniques and therapeutics. Algal Res. 24, 97-110.

56. SULERIA, H. A. R., S. OSBORNE, P. MASCI and G. GOBE (2015): Marine-Based Nutraceuticals: An Innovative Trend in the Food and Supplement Industries. Mar. Drugs 13, 6336-6351.

57. SUZUKI, T. (2008): Chemistry, Metabolism, and Chemical Detection Methods of Pectenotoxins. In: Botana, L. M.: Seafood and Freshwater Toxins, Pharmacology, Physiology and Detection, CRC Press, Boca Raton (343-380).

58. TAKATA, K., M. MIZUTA and T. MONDEN (1994): Reduction in toxicity of PSP-infected oysters by heat treatment. J. Food Hyg. Soc. Japan. 35, 624-630.

59. TAKATA, Y., S. SATO, D. V. HA, U. M. MONTOJO, T. LIRDWITAYAPRASIT,S.KAMOLSIRIPICHAIPORN, Y. KOTAKI, Y. FUKUYO and M. KODAMA (2009): Occurrence of domoic acid in tropical bivalves. Fish. Sci. $75,473-480$.

60. TAYLOR, M, L. MCINTYRE, M. RITSON, J. STONE, R. BRONSON, O. BITZIKOS, W. ROURKE, E. GALANIS, and Outbreak Investigation Team (2013): Outbreak of Diarrhetic Shellfish Poisoning Associated with Mussels, British Columbia, Canada. Mar. Drugs. 11, 1669-1676.

61. TODD, E. C. D. (1997): Seafood-associated diseases and control in Canada. Rev. Sci. Tech. Off. Int. Epiz. 16, 661-672.

62. TUBARO, A., P. DURANDO, G. DEL FAVERO, F. ANSALDI, G. ICARDI, J. R. DEEDS and S. SOSA (2011): Case definitions for human poisonings postulated to palytoxins exposure. Toxicon. 57, 478-495.

63. UJEVIĆ, I., R. ROJE, Ž. NINČEVIĆ-GLADAN and I. MARASOVIĆ (2012): First report of Paralytic Shellfish Poisoning (PSP) in mussels (Mytilus 
galloprovincialis) from eastern Adriatic Sea (Croatia). Food Control 25, 285-291.

64. VALDIGLESIAS, V., M. V. PREGO-FARALDO, E. PÁSARO, J. MÉNDEZ and B. LAFFON (2013): Okadaic Acid: More than a Diarrheic Toxin. Mar. Drugs. 11, 4328-4349.

65. VAN DOLAH, F. (2000): Marine Algal Toxins: Origins, Health Effects, and Their Increased Occurrence. Environ. Health Perspect. 108, 133-141.

66. VISCIANO, P., M. SCHIRONE, M. BERTI, A. MILANDRI, R. TOFALO and G. SUZZI (2016): Marine Biotoxins: Occurrence, Toxicity, Regulatory Limits and Reference Methods. Front. Microbiol. 7 (1051).

67. WANG, J., Y. WANG, L. LIN, Y. GAO, H. HONG and D. WANG (2012): Quantitative proteomic analysis of okadaic acid treated mouse small intestines reveals differentially expressed proteins involved in diarrhetic shellfish poisoning. J. Proteomics 75, 2038-2052.

68. WIESE, M., P. M. D'AGOSTINO, T. K. MIHALI, M. C. MOFFITT and B. A. NEILAN (2010): Neurotoxic Alkaloids: Saxitoxin and Its Analogs. Mar. Drugs. 8, 2185-2211.

69. WU, X., L. HOU, X. LIN and Z. XIE (2019): Application of Novel Nanomaterials for Chemoand Biosensing of Algal Toxins in Shellfish and Water. In: Wang, X. and X. Chen: Novel Nanomaterials for Biomedical, Environmental and Energy Applications. Elsevier, Amsterdam (353-414).

\section{Phycotoxins in marine organisms - a potential threat to consumer safety}

Kristina KVRGIĆ, BSc, Expert Associate, Natalija DŽAFIĆ, DVM, MSc, Expert Associate, Croatian Veterinary Institute, Veterinary Centre Rijeka, Rijeka, Croatia; Jelka PLEADIN, BSc, Biotech., PhD, Scientific Advisor Tenure, Associate Professor, Croatian Veterinary Institute, Zagreb, Croatia

Phycotoxins are natural chemical contaminants that include azaspiracids (AZAs), okadaic acid (OAs), pectenotoxins (PTXs), yessotoxins (YTXs), cyclic imines (CIs), domoic acid (DA), saxitoxins (STXs) brevetoxins (BTXs), ciguatoxins (CTXs) and palytoxins (PITX). The results of previous research have indicated the frequent occurrence of phycotoxins in marine organisms, and it is known that these substances can have a detrimental effect on both the environment and human health, since in addition to acute toxicity, some are tumour promoters, i.e., they show mutagenic and toxic effects in the body even when present in low concentrations. Therefore, in order to protect consumers, the legislation has set maximum levels (MLs) for phycotoxins in bivalve molluscs, echinoderms, tunicates and marine gastropods (EC 853/2004; EU 786/2013), although some, such as cyclic imines, have not yet been included in monitoring programmes and MLs have not yet been determined by the legislation. In further research, using confirmatory highly specific analytical methods to test for the occurrence of these substances, it is necessary to examine their effects on a more sensitive part of the population due to possible synergistic effects in the body to determine cooccurrence, and to assess consumer exposure due to the presence of these toxic substances intended for consumption. This paper provides an overview of the literature on the properties of the most important representatives of phycotoxins, their toxic effects in the body and their occurrence in different types of marine organisms.

Key words: phycotoxins; consumer safety; marine organisms; incidence; toxicity 